\title{
Students' perception of traditional teaching- learning process in Physiology. An insight to study Absenteeism in medical students
}

\author{
Warkar, A.B. ${ }^{1}$, Asia, A.A. ${ }^{2}$
}

\begin{abstract}
Background: Worldwide there is a major concern on students' absenteeism for university education. Professional course like medicine requires high attendance by students. The undergraduate medical education should produce physicians with adequate knowledge of health and disease, reasonable medical skills and a healthy attitude towards patients and their families. With this background the study is conducted to know the causes of absenteeism among students, their experiences and perceptions regarding ongoing teaching learning educational programme.

Methods: We conducted a cross sectional study using a pretested self-administered structured questionnaire to 140 first professional MBBS course students. The pre validated questionnaire was pertaining to reasons for absenteeism, teaching learning methods, process of evaluation, mainly in respect to students' experiences and their perception. The attendance and marks were taken from available database. The data were entered and analysed by using SPSS15 software version.

Results: Students favoured interactive lectures (84\%), shorter duration (70\%), Self-Study, $(45 \%)$ and clinical orientation (68\%). They appreciated audiovisual aids (95\%) applied physiology, (85\%) frequent evaluation, (54\%). Qualities highly rated in a teacher were teaching skills, knowledge and approachability. Absenteeism was largely attributed to tiring schedule, monotonous teaching style and priority to self-study.

Conclusion: Students preferred self-directed learning, short lectures, and use of multimedia, interactions and clinical orientation. Students as well as the teacher attribute, teaching methodologies play a role in absenteeism. Optimum utilization of teaching hours with learner oriented teaching approach and adapting newer teaching technologies may reduce the absenteeism and enhance the educational Programme effectively.
\end{abstract}

Keywords: Attendance, feedback, teaching methodology, performance.

${ }^{1}$ Anil B. Warkar

Associate Professor,

Physiology Dept.

Govt. Medical College, Akola, Maharashtra India.

${ }^{2}$ Anju A. Asia

Assistant Professor, Physiology Dept. Govt. Medical

College, Akola, Maharashtra, India.

\section{Author for correspondence:-}

Dr. Anil B. Warkar,

Associate professor,

Physiology Dept. Government Medical College and General Hospital, Akola, Maharashtra, 444001. India.

Email id:warkar.anil@gmail.com

\section{Introduction}

Nowadays the pace of change in medical education has changed dramatically that is driven by exponential knowledge and need to train a large group of learners using limited resources. There is also a shift towards outcome based education which is parallel with an increasing awareness that the process of learning is as important as outcome. The medical curriculum is being redesigned with new teaching learning approaches, so as to ensure that students acquire appropriate clinical \& scientific knowledge along with practical, procedural \& communication skills at (Jordan \& Cohen, 2001). Absenteeism lectures 
is a major concern in our Maharashtra University of Health Sciences (MUHS), India, reflects a lack of interest in traditional classroom learning by medical students. This has become a significant issue in the medical colleges affiliated to MUHS, as the trend continues for successive years of MBBS course. University has explicit policies regarding the mandatory attendance in lectures, laboratory and practical sessions. Despite the strict rules, the absenteeism is a growing problem; a phenomenon that is also on rise in universities worldwide (Moore, 2006; BinSaeed et al., 2008; Gatherer \& Manning, 1998). Surprisingly the performance of the students in university examinations is reported to be better in spite of less attendance, clearly indicating that self-study is the preferred mode of learning by the students.

Medical students must demonstrate \& practice the pillars of professionalism, altruism, integrity, responsibility \& respect (Fard \& Asghari, 2010). But then with the pace of change in the medical education the type of the learning experiences by the students cannot be left untouched. Do the students expect any change in the teaching learning process? What are the students' expectations from the teacher so that the existing teaching learning process can be made more effective? Moreover absenteeism among students in other professional courses has been addressed in several studies but the performance by the students have not been evaluated (Marburger, 2001; Koh, 1998). The cause of absenteeism in medical students has also received little attention in literature. University Student's Expectations of Study (USET) (Sander et al., 2000) is a feedback questionnaire developed for obtaining students preferences for teaching, carried out with UK Open University students in the field of medicine. Such questionnaire takes student's expectations and views into consideration for making the teaching-learning process more effective. Hence our study is intended with the following objectives:

\section{Objectives}

1. To assess students experiences and expectations regarding current teaching- learning practices.

2. To study the causes for student absenteeism.

3. To elicit suggestions from students in order to enhance effective teaching learning process.

\section{Materials and methods}

After obtaining approval from the Institutional ethical committee (IEC) the study was conducted in the Department of Physiology, Govt. Medical College, Akola (M.S.) This was a cross sectional study based on an structured pre-tested questionnaire (Lata et al., 2008). 140 students of first MBBS were administered a questionnaire covering two major aspects routinely followed i.e. teaching learning methods \& evaluation pattern. The question regarding the students' experiences in their tenure of $1^{\text {st }}$ year, MBBS pertained to the learning methods, teaching methods, teaching aids, utility of applied physiology, evaluation pattern \& causes of absenteeism. Whereas questions pertaining to their expectations were based on time span of lecture, interaction, clinical orientation \& evaluation system. It comprised of four types of questions namely alphabetical grading, selection of an appropriate option, assertive/non-assertive option and suggestions. The validation of questionnaire: validation was done by the Faculty of Institutional Medical Education Unit. The questions were explained in clear terms at the beginning so that the respondents were clear about the direction of responses. After getting the consent from students, the questionnaire was given at the end of the term which had to be answered by the students in 45 minutes, with no undue pressure from any faculty member. Students were asked not to disclose their identities in any form in order to obtain a fair opinion. Confidentiality of the students was assured so that they could answer the question without any bias. Students' attendance and marks were obtained from database. Completed response sheets were statistically analysed using SPSS15 software. The results were expressed as frequency

\section{Results}

The number of students who answered questionnaire were $140(n=140)$. Results were divided in to four aspects. Teaching-learning approach, reasons for absenteeism, qualities appreciated in a good teacher and assessment.

\section{Teaching - learning process}

The chosen preferences for learning methods namely self-study, lectures and lectures cum demonstrations (LCD) are highlighted in Table 1 . $94 \%$ of the students preferred combination 
Table 1: Learning Methods. $(N=140)$

\begin{tabular}{lccc}
\hline \multicolumn{1}{c}{ Method } & $\begin{array}{c}\text { Very Helpful } \\
\%(\text { No) }\end{array}$ & $\begin{array}{c}\text { Less Helpful } \\
\%(\text { No) }\end{array}$ & $\begin{array}{c}\text { Helpful } \\
\%(\text { No) }\end{array}$ \\
\hline Self-study & $45(63)$ & $42(59)$ & $13(18)$ \\
Lecture & $17(24)$ & $59(83)$ & $24(33)$ \\
LCD & $26(36)$ & $24(33)$ & $50(70)$ \\
\hline
\end{tabular}

Table 2: Reasons for Absenteeism. $(N=140)$

\begin{tabular}{lcc}
\hline Reasons & $\%$ & Number \\
\hline Tiring schedule\& long Duration & 56 & 78 \\
Self-Learning & 52 & 72 \\
Lack of Motivation & 30 & 42 \\
Teaching Style & 19 & 26 \\
\hline
\end{tabular}

Table 3: Utility of the following modes of teaching Learning processes for better Results. $(N=140)$

\begin{tabular}{lcc}
\hline \multicolumn{1}{c}{ Methodology } & $\%$ & Number \\
\hline Better Lectures & 36 & 50 \\
Regular Tests & 48 & 67 \\
Better Practical & 9 & 13 \\
Small Group Teaching & 7 & 10 \\
\hline
\end{tabular}

Table 4: Showing Batch wise average percentage of Students Absenteeism \& and average final result score for last three years

\begin{tabular}{lll}
\hline Batch( Year) & \% Absenteeism & \% Result Scores \\
\hline $2011-2012$ & $66.4 \%$ & $94.3 \%$ \\
$2012-2013$ & $61.9 \%$ & $91.2 \%$ \\
$2013-2014$ & $63.8 \%$ & $92.7 \%$ \\
\hline
\end{tabular}

The $\%$ of student's absenteeism is batch wise at the end of $2^{\text {nd }}$ Term. The $\%$ of result is the final university overall result of the batch for respective years. 


\section{Preferred type Of Lecture}

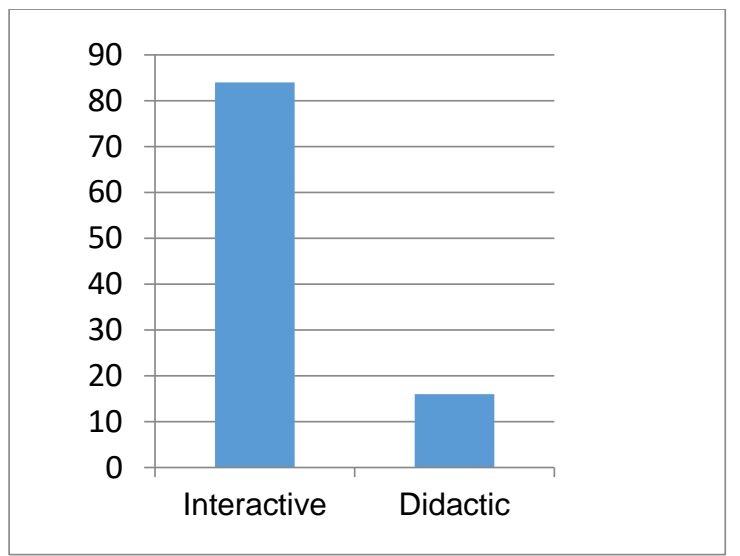

Interactive Lecture-84\%, Didactic Lecture-16\%

\section{Figure 1: Qualities of a teacher}

of whiteboard and power point helpful to them, $5 \%$ of the students' preferred white board only \& $1 \%$ power point only. Interactive lectures were desired by $84 \%$ of the students whereas $16 \%$ wanted didactic lectures (Fig.1). Majority of the students (85\%) opted for the applied physiology giving a good response and only $15 \%$ found to be less useful. $68 \%$ of the students wanted clinical orientation to be started within first year whereas $32 \%$ did not prefer it. A 45 minute lecture was preferred by $70 \%$ students, $26 \%$ wanted 60 minute lecture and $4 \%$ wanted a 30 minute lecture.

\section{Reasons for Absenteeism}

As shown in Table 2, 56\% of students opined that tiring schedule led to absenteeism frequently, $52 \%$ cited self-study as the preferred mode of learning, $27 \%$ cited teacher's lack of motivation was the cause of absenteeism, most of the time for $30 \%$ of the students and monotonous teaching style was opted by $19 \%$ students.

\section{Qualities appreciated in a good teacher}

Good teaching skills 34\%, knowledgeable $36 \%$ \& approachable $31 \%$ were the important qualities, most sought after as a good teacher (Fig.2). Enthusiasm, punctuality \& organization were the lower rank qualities amongst the most desirable qualities of a good teacher.

\section{Assessment}

Students appreciated terminal \& preliminary examinations comprising of MCQs, Short answer questions \& long answer questions.

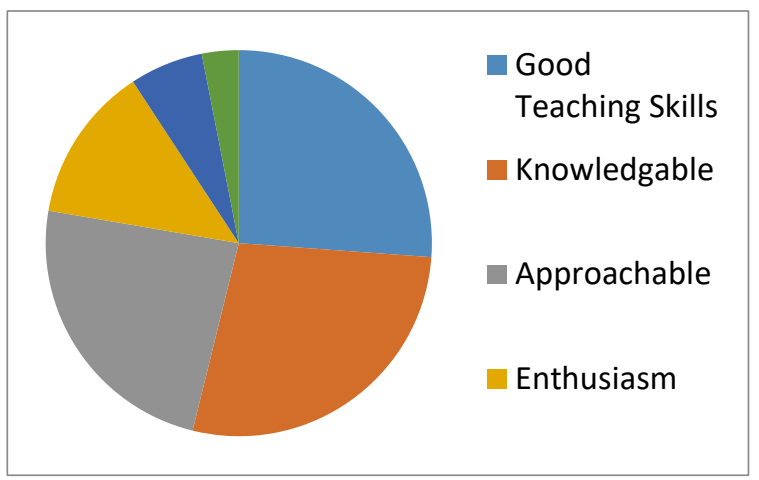

Good teaching skills-34\%, Knowledgeable-36\%, Approachable-31\%, Enthusiasm-18\%, Organization-7\% Punctuality-4\%.

\section{Figure 2}

$68 \%$ felt these to be very helpful. $54 \%$ found part completion tests at the end of completion of each system, having similar pattern as terminal exams helpful. $38 \%$ of the students appreciated MCQs as the method of evaluation, short answer questions were liked by $34 \%$ while $28 \%$ felt that long answer questions were better.

There were some useful suggestions given by the students like problem solving at the end of every lecture session (35\%), MCQ practice sessions $(10 \%)$, clear simple and audible language of the presentation (48\%) and counselling for weaker students (7\%). As per Table 4, the absenteeism in first MBBS students is declining for consecutive three batches, still the students' performance in final University examination is better $(94.3 \%, 91.2 \%$ and $92.7 \%)$.

\section{Discussion}

First year in medical course is a transit phase where students shift from $10+2$ pattern of learning, predominantly exam cantered, preferring self-study rather than Institutional teaching. This could be the reason that probably students are not adapting the teaching methodologies of the professional colleges. The important reasons stated by the students for absenteeism were tiring teaching learning schedule, preference of self-learning, lack of motivation in learning, longer lecture duration and some of them also commented about monotonous teaching style in lectures. Trevena (2003) in his study found that students appreciated self-directed learning in basic and 
clinical sciences more than traditional lectures. A lengthy monotonous, teacher centred large group learning is always less interesting with little perception by students and lack of interest in classroom learning. Individual attitude and motivation are the key factors for absenteeism (Dhaliwal, 2003). These findings are in consistent with the findings from study on absenteeism by Desalegn et al. 2014).

Students' preference to PowerPoint with white board is justified as use of technology in medical profession, improves the learning experiences and also complements the traditional teaching provided it should be well planned. Any technology in teaching- learning process is a powerful tool, applying it can facilitate our teaching, maximize its potential benefits and help us to improve as good medical educators. Interactive Teaching learning sessions received an overwhelming response. Similar findings of interactive learning sessions were also reported by Hashmi et al. (2010). Students value the opportunity to discuss the content rather than passive learning. Two way communication assists in learning process and aids retention. Through interaction, a high level of cognitive learning and communication skills are achieved (Hashmi et al., 2010). No doubt the well organized and carefully presented lectures provide up to date view of subject but students must be physically present and be attentive (Shatter, 1998).

Early clinical orientation and applied physiology were very much appreciated by the students in our study. McMillan and Wenger (1987) reported of better attendance on introducing clinical oriented topics in preclinical years. In students' perception, they see the relevance and value of what they are learning with clinical orientation. In fact in the developing countries like India, there is an emphasis on communication skills and ethics. Students preferred a 45 minute lecture. It highlights the fact that concentrating on a passive teaching session for one hour duration is tiresome resulting in growing apathy towards lectures. It is in accordance with the other studies (Lata et al., 2008; Hashmi et al., 2010). Complementing lectures with interactions, quizzes and illustrations seem the way out.

In our study, regular assessment with part completion tests were found to be helpful for students. MCQ were the most preferred mode of evaluation followed by SAQs. As per students' perception, it helps them to prepare for their post graduate entrance exams. Frequent formative evaluation in place of stereotyped evaluation pattern is more effective. Regular tests were equally appreciated by students, for achieving better results whereas some students found better lectures necessary for improving results (Table 3).

The top three important qualities selected for a good teacher were good teaching skills, being knowledgeable and approachable. Students appreciated well-structured sessions with consistency in teaching. They wanted a teacher with content expertise, good facilitating skills and enthusiasm for teaching. Snvaita and Paul (2012) quoted the qualities of a good teacher, as approachable, knowledgeable, enthusiastic, logical, and reliable, role model, learner and a mentor. Becoming an effective teacher is a continual refinement in teaching. A medical teacher should exhibit good qualities and role model for students.

Our study noted better results in the university examination performances by the students and there was consistency in the results in previous two to three batches in spite of more absenteeism as shown in Table 4. Similar findings were reported by Horton et al. (2012). It clearly indicates the impact of self -study by the learner on performance and achievements. But then are we preparing our future physicians to be exam oriented? And if so, then are we sure that the health care of the society and population will be properly taken as per the need? Medical students must demonstrate \& practice the attributes of professionalism. Attendance in all scheduled learning sessions demonstrates professionalism and shows respect for faculty \& colleagues (Trice et al., 2000).

With these students' perceptions and performances, some very important aspects related with medical education need attention by medical educators. First, in spite of absenteeism, better performance in part completion as well as in university examinations may reflect on process of evaluation. Are our evaluation methods properly assessing the learning objectives and what it has to assess. Second, is our university curriculum as per the need of the current pace or is there any need for reform in existing curriculum. Third, more Medical Education Technology trainings should be given to faculty, instructors in order to improve the teaching skills that could help to improve students' attendance (Gatherer \& Manning, 1998). Subramaniam et al., (2013) in their study reported an increase in attendance by 15 to 20 $\%$ by introducing Self Directed Learning (SDL) 
and Problem Based Learning (PBL) along with conventional teaching technology. Faculty should regularly revise the training courses which can bring about the various styles in teaching and make it effective to attract more learning by the students.

\section{Conclusion}

Our study concludes that students prefer SDL compared to teacher centred, monotonous, tiring, lengthy traditional learning. Instead of that, they prefer shorter lecture with multimedia, interaction and clinical orientation. Optimum utilization of teaching hours shifting from being teacher- centred to learner- oriented is necessary. Therefore integrated teaching, problem based learning, small group teaching, interactions are very much essential to incorporate in teaching- learning process. Not only student's behaviour but also teacher's attributes and teaching methodologies appear to play a role in student's absenteeism from lectures. The faculty must adapt newer teaching technologies so as to keep pace with the ongoing teachers training Programmes and applying newer methodologies can somehow minimize the absenteeism among the medical students. Absenteeism at wider level will have detrimental consequences on social values, health status and productivity of the country and therefore absenteeism has to be taken into account.

\section{Limitations}

One limitation of our study in assessing the problem of student absenteeism is the study design. It is a descriptive cross sectional study without any quantitative component that does not allow for gathering detailed information to establish casualty between absenteeism and its predictors. The data were collected based on self-reporting on non-attendance, which can be subject to recall bias.

\section{Recommendation}

Our study recommends further such studies in other medical institutes affiliated to our university \& to focus on evaluation methods to study the proper outcome of ongoing teaching learning Programme. Curriculum reform, if any needed, in the existing educational Programme of the university, should be considered. Prompt remedial measures should be taken to prevent the cycle of absenteeism. Faculty must encourage positive attitudes towards the importance of class attendance for students. Regular teachers training for faculty to help them improve their teaching methodologies could be a useful intervention.

\section{Acknowledgement}

Authors wish to thank the Medical Education Unit Govt. Medical College, Akola, for constant support and guidance to conduct this project.

\section{Conflicts Of Interest}

No potential conflict of interest relevant to this article is reported.

\section{References}

BinSaeed,A.A., al-Otaibi, M.S., al-Ziyadi, H.G., Babsail, A.A. \& Shaik, S.A. (2009) Association between student's absenteeism at a medical college and their academic grades, The journal of The International Association of Medical Science Educators,19,4, pp. 155-159.

Desalegn, A.A., Berhan, A. \& Berhan, Y. (2014) Absenteeism among medical and health science undergraduate students at Hawassa University, Ethiopia, BMC Medical Education,14,1, pp. 81.

Dhaliwal, U.P.R.E.E.T. (2003) Absenteeism and underachievement in final year medical students, National Medical Journal of India, 16, 1, pp. 34-36.

Fard, N. \& Asghari, F. (2010) Ethics in medical students, Medical Education, 44,7, pp. 723-730.

Gatherer, D. \& Manning, F. C. (1998) Correlation of examination performance with lecture attendance: a comparative study of first year biological sciences undergraduates, Biochemical Education, 26, 2, pp. 121-123.

Hashmi, N.R., Daud, S. \& Manzoor, I.(2010) Medical education: views and recommendations by final year MBBS students of a private medical college in Lahore, Journal of the College of Physicians and Surgeons Pakistan ,20,2 , pp. 93-97.

Horton, D.M., Wiederman, S.D. \& Saint, D.A. (2012) Assessment outcome is weakly correlatedwith lecture attendance: influence of learning style and use of alternative materials, Advances In Physiology Education, 36 , 2, pp. 108-115.

Jorden, J. \& Cohen (2001) The argument for global standard for medical education, The Meducator, 1 , 3, pp. S8-S9.

Koh, L. (1998) Students absent registered, Nursing Times, 94, 23, pp. 76-77.

Lata,H., Walia, L. \& Gupta, V. (2008) Student feedback on teaching and evaluation methodology in Physiology, South East Asian Journal Of Medical Education, 2,1 , pp. 31-36.

Marburger, D.R. (2001) Absenteeism and undergraduate exam performance, The Journal of Economic Education, 32, 2, pp. 99-109.

McMillan,D.E. \& Wenger, G.R. (1987) Effects of curriculum and format changes in a medical 
pharmacology course, 1983 to 1987,Academic Medicine ,62, 10, pp. 836-841.

Moore, R. (2006 ) The importance of admissions scores and attendance to first year performance, Journal of The First Year Experience \& Students In Transition,18, 1, pp. 105-125.

Sander, P., Stevenson, K., King, M. \& Coates, D. (2000) University students' expectations of teaching, Studies in Higher Education, 25, 3, pp. 309-323.

Shatter, J.H. (1998) Instructional methods, Academic Medicine, 73, 9 , pp. S38-S45.

Snvaita, R., Paul, B. (2012) Effective teaching skills; How to become a better medical educator, BMJ Careers, pp. 1-4.
Subramaniam, B.S., Hande, S. \& Komattil, R. (2013) Attendance and achievement in Medicine: Investigating the impact of attendance policies on acadamic performance of medical students, Annals of Medical and Health Sciences Research, 3,2, p. 202.

Trevena L. (2003) What medical students value in a population health tutor: characteristics for consideration in staff recruitment and development, Education For Health-Abingdon Carfax Publishing Limited, 16,1, pp. 51-58.

Trice, A.D., Holland, S. A. \& Gagne, P.E. (2000) Voluntary class absences and other behaviours in college students: An exploratory analysis, Psychology Reports, 87, 1, pp. 179-182. 